\title{
Inverted-Takotsubo Cardiomyopathy in a Patient with Pulmonary Embolism
}

\author{
Seung-Hyun Lee, MD, Dong-Hyun Kim, MD, Min-Suk Jung, MD, Jang-Won Lee, MD, \\ Kyung-Min Nam, MD, Young-Sun Cho, MD, and Joon-Hoon Jeong, MD \\ Cardiology Division, Department of Internal Medicine, Wallace Memorial Baptist Hospital, Busan, Korea
}

As the use of early coronary angiography and echocardiography become widely available in the setting of acute coronary syndrome, the gradual increase for variant forms of transient left ventricular (LV) apical ballooning syndrome have been recognized. This syndrome usually occurs in women and is frequently elicited by an intense emotional, psychological, and physical event. While the patients' characteristics between typical and non-typical LV ballooning syndrome seem to differ, the presentation, clinical features, and reversibility of LV wall motion abnormalities are similar. We present a middle-aged woman who experienced inverted takotsubo cardiomyopathy triggered by pulmonary embolism. To the best of our knowledge, this case is particularly unique and is rarely reported in the disease entity. (Korean

Circ J 2013;43:834-838)

KEY WORDS: Stress cardiomyopathy; Takotsubo cardiomyopathy; Pulmonary embolism.

\section{Introduction}

Takotsubo cardiomyopathy is characterized by transient left ventricular (LV) regional wall motion abnormalities and usually involves apical segments in the absence of significant coronary artery stenosis. In the recent years, several cases on atypical forms of transient LV ballooning syndrome have been reported. The pathophysiological mechanisms remain unclear, however, the catecholamine excess and increased sympathetic activity are likely to play a pivotal role in triggering this syndrome. ${ }^{1-3)}$ In this report, we describe an unusual case of a 38-year-old woman who had pulmonary embolism (PE) and reverse takotsubo cardiomyopathy. PE has been listed as stressors of stress-induced cardiomyopathy, ${ }_{1}^{2 / 3)}$ because the pain and

Received: April 8, 2013

Revision Received: June 14, 2013

Accepted: August 12, 2013

Correspondence: Joon-Hoon Jeong, MD, Cardiology Division, Department of Internal Medicine, Wallace Memorial Baptist Hospital, 200 Geumdanro, Geumjeong-gu, Busan 609-728, Korea

Tel: 82-51-580-1202, Fax: 82-51-583-6200

E-mail: jjhoonmd@hanmail.net

- The authors have no financial conflicts of interest.

This is an Open Access article distributed under the terms of the Creative Commons Attribution Non-Commercial License (http://creativecommons. org/licenses/by-nc/3.0) which permits unrestricted non-commercial use, distribution, and reproduction in any medium, provided the original work is properly cited. the decreased perfusion within the lung related to PE probably cause a release of catecholamines. ${ }^{455}$ However, it is uncommon to present reverse types of stress-induced cardiomyopathy in the setting of PE for our patient.

\section{Case}

A 38-year-old woman with no history of cardiac diseases or cardiac risk factors was referred to our emergency department because of chest discomforts, arrhythmia and shortness of breath after the surgery. A few days before she had fallen off the ladder and underwent surgery for right lateral malleolar fracture under spinal anesthesia. Physical examination revealed vital signs as follows: blood pressure $90 / 60 \mathrm{~mm} \mathrm{Hg}$, heart rate 75 beats/min, body temperature $36.7^{\circ} \mathrm{C}$, respiratory rate $22 / \mathrm{min}$ and oxygen saturation $88 \%$ on room air. Oxygen saturation was increased to $94 \%$ after giving $3 \mathrm{~L} \mathrm{O}_{2}$ via nasal prongs. The electrocardiogram (ECG) recording showed sinus rhythm, ST-segment depression in $V_{3}$ through $V_{51}$ and there were no typical features of ECG abnormalities associated with PE such as sinus tachycardia, $\mathrm{S}_{1} \mathrm{O}_{3} \mathrm{~T}_{3}$ pattern, complete and incomplete $\mathrm{RBBB}$, and $T$ wave inversion (Fig. 1). Chest radiography showed diffuse increased bronchovascular lung markings with mild congestion and edema, D-dimer was elevated to $1572 \mathrm{ng} / \mathrm{mL}$ (normal reference range $0-243 \mathrm{ng} / \mathrm{mL}$ ) and altered results of the arterial blood gas analysis (pH 7.42/pCO $25.8 \mathrm{~mm} \mathrm{Hg} / \mathrm{pO}_{2} 69.7 \mathrm{~mm} \mathrm{Hg} / \mathrm{HCO}_{3} 16.4 \mathrm{mmol} /$ 


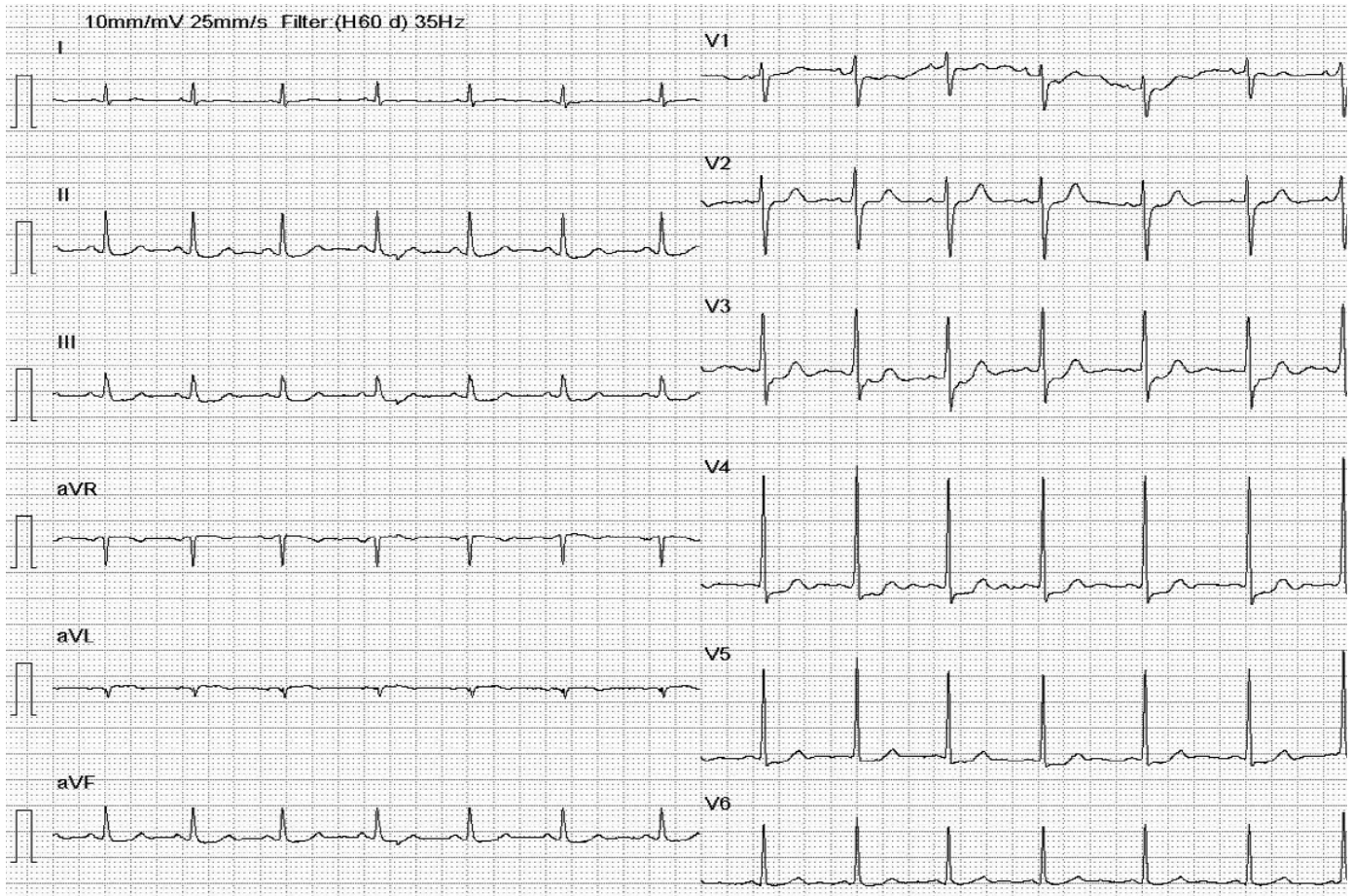

Fig. 1. Electrocardiogram on admission.
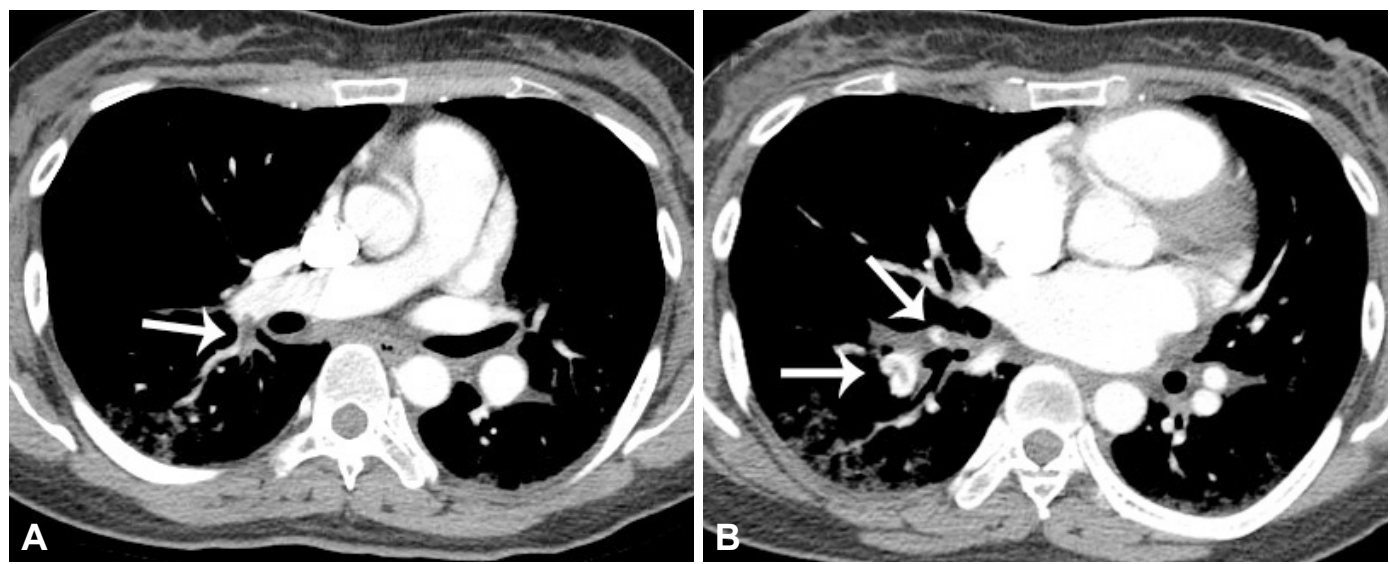

Fig. 2. Computed tomography in a 38-year-old woman with pulmonary embolism. A: this shows an intraluminal filling defect in the right lower lobe pulmonary artery (arrow). B: the clot is also visible in anterior and posterior basal segment arteries (arrows).

L) aroused suspicion of PE. It was confirmed by computed tomography and thus, therapy with heparin infusion was initiated (Fig. 2). Other laboratory findings indicated white blood cell counts of 10000/ $\mathrm{mm}^{3}$; hemoglobin $9.7 \mathrm{~g} / \mathrm{dL}$; platelet count $275000 / \mathrm{mm}^{3}$; C-reactive protein $0.0 \mathrm{mg} / \mathrm{dL}$; alanine aminotransferase $18 \mathrm{U} / \mathrm{L}_{\text {; }}$ aspartate aminotransferase $39 \mathrm{U} / \mathrm{L}$; total bilirubin $0.46 \mathrm{mg} / \mathrm{dL}$; and serum creatinine $0.7 \mathrm{mg} / \mathrm{dL}$. The cardiac enzyme levels were elevated with a peak level of creatine kinase-MB isoform $27 \mathrm{ng} / \mathrm{mL}$ (normal reference range 0-3.6 $\mathrm{ng} / \mathrm{mL}$ ) and troponin I $5.30 \mathrm{ng} / \mathrm{mL}$ (normal reference range $0-0.1 \mathrm{ng} / \mathrm{mL}$ ). Transthoracic echocardiography showed hypokinesia of mid/base segments of LV with hypercontraction of apical segments and reduced ejection fractions estimated at $47 \%$ with no significant valvular dysfunctions. Right ventricular systolic dysfunction or dilated right ventricle was not found, and yet an estimated systolic pulmonary artery pressure increased mildly to $43 \mathrm{~mm} \mathrm{Hg}$ on the assumption of right arterial pressure of $10 \mathrm{~mm} \mathrm{Hg}$ (tricuspid regurgitation peak velocity: $2.87 \mathrm{~m} / \mathrm{s}$ ) (Fig. 3). Coronary angiography was immediately performed within an hour of admission and ruled out obstructive atherosclerotic diseases. She was managed with medical therapy using $\beta$-blocker and diuretics. ${ }^{2336(6) 7}$ Angiotensin converting enzyme inhibitors was not indicated because of mild hypotensions. After the medical treatment, the patient was presented free of symptoms for the following few days. Transthoracic echocardiography was undergone 1 week after her admission and showed 

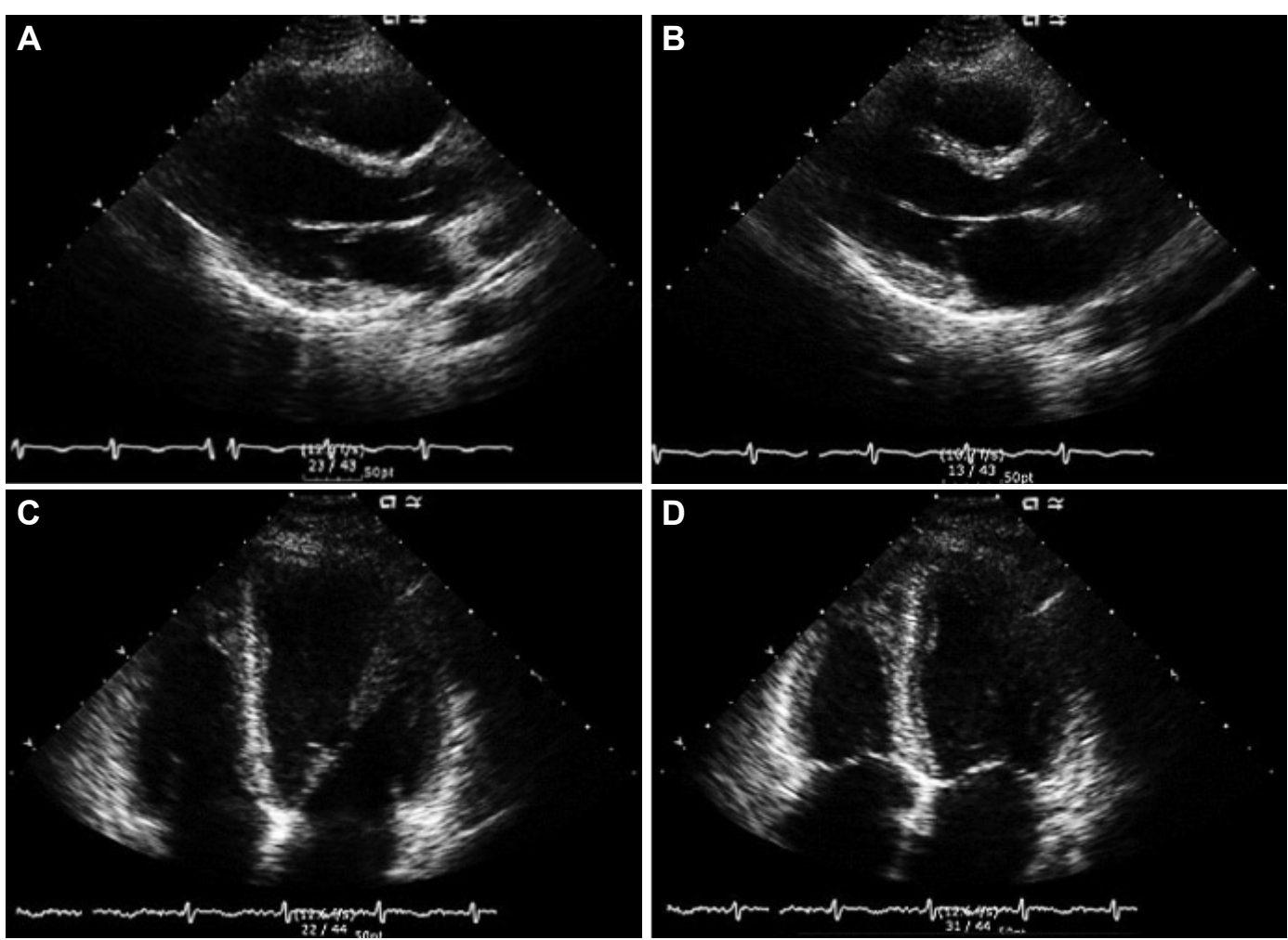

Diastole

Systole

Fig. 3. Transthoracic echocardiography at the time of pulmonary embolism shows severe left ventricular systolic dysfunction with hypokinesia of the base and mid ventricular segment and hypercontractility of the apex. A and B: parasternal long-axis view in diastole and systole. C and D: apical four-chamber view in diastole and systole.

improvements in ejection fractions of 58\% with no wall motion abnormalities (Fig. 4). ECG was normalized within 10 days. The patient was discharged in good clinical conditions and remained well after 3 months of follow-up.

\section{Discussion}

Takotsubo cardiomyopathy, also known as apical ballooning syndrome, is generally characterized as severe, reversible LV dysfunctions of apical segments. Variants, the non-apical ballooning syndrome, have been recognized as reversed, mid-ventricular, and localized type based on the involvement of the left ventricular. ${ }^{8)}$ Our case is consistent with the reverse type, hyperdynamic apex and akinesia of the mid/base segments of LV. Compared to typical LV ballooning syndrome, this atypical form of transient LV ballooning syndromes have different characteristics of patients. ${ }^{6 / 8)}$ Hahn et al. ${ }^{6}$ described that patients with atypical transient LV ballooning syndrome were younger with the mean age of 36 and had fewer coronary risk factors such as hypertensions, diabetes, and smoking habits. Also, T wave inversion in an ECG was found as less similar to our patient. The pathophysiological mechanisms of takotsubo cardiomyopathy remain elusive. However, according to the recent reviews and many published clinical cases, the excessive catechol- amine and exaggerated sympathetic activities are greatly accountable. $^{1-3)-11)}$ Differences in anatomical location and density of cardiac adrenergic receptors and the degree of sympathetic activity may explain the wall motion abnormalities as seen in the typical and reverse types. ${ }^{811112)}$ Clinical presentations and transient nature of LV wall motion abnormalities in reverse type are similar to those of classic takotsubo cardiomyopathy which could indicate a possibility of sharing pathophysiological mechanisms, and yet, none of related evidences has been revealed. Estrogens, which have a protective effect on cathecholamine-induced toxicity, appear to have influences on the preponderances of postmenopausal women toward takotsubo cardiomyopathy. ${ }^{1 / 2) 133}$ However, further researches for the interaction of catecholamines and estrogen are necessary to clarify the underlying mechanisms of stress-induced cardiomyopathy at a younger age without estrogen deficiency, and the specific reasons for rare presentations of men with physiologically estrogen-deficient. Takotsubo cardiomyopathy has been described with a wide range of emotional or physical stressful triggers. Herein, we report a middle-aged woman with inverted takotsubo cardiomyopathy in the setting of $\mathrm{PE}$, which is a rare coexistence for this association. The exact mechanisms of the relation between PE and atypical takotsubo cardiomyopathy are not clear. But increased catecholamine levels during severe pain and perfusion defect within the lung re- 

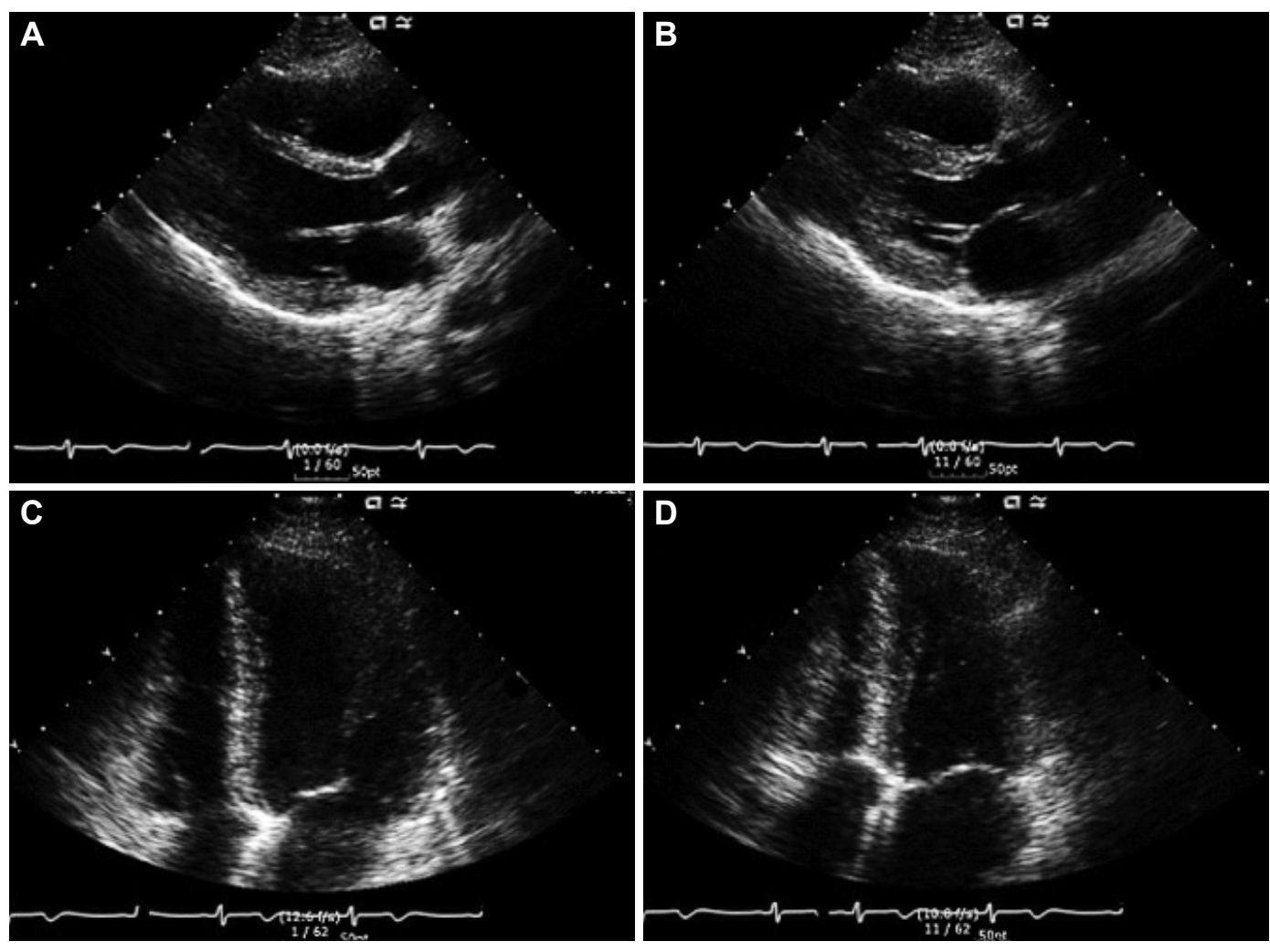

Diastole

Systole

Fig. 4. A follow-up echocardiography 1 week later shows improved base and mid portions of ventricle and nearly normalized cardiac functions. A and B: parasternal long-axis view in diastole and systole. C and D: apical four-chamber view in diastole and systole.

lated to PE seem to result in the development of LV wall motion abnormalities. ${ }^{4 / 5)}$ In this case, it is difficult to detect PE and reverse takotsubo cardiomyopathy independently, due to the fact that both clinical features mimic acute coronary syndromes. Despite of the poor sensitivity and specificity of ECG abnormalities to diagnose PE and inverse takotsubo cardiomyopathy, there are several frequent features including sinus tachycardia, both complete and incomplete RBBB, $\mathrm{S}_{1} \mathrm{O}_{3} \mathrm{~T}_{3}$ pattern, and ST-segment elevation, non specific $\mathrm{T}$ wave abnormalities, respectively. ${ }^{24-6)} \mathrm{A}$ transthoracic echocardiography (TE) provide the evidence of PE such as right ventricular systolic dysfunctions and pulmonary hypertensions, ${ }^{4 / 5)}$ and stress-induced cardiomyopathy may have right ventricular involvement which is associated with more severe impairments in LV systolic functions. ${ }^{14)}$ Thus, it is important to carry out ECG promptly, TIE and coronary angiography based on a high degree of clinical suspicions. Further research is needed to elucidate this relationship and different pathophysiological mechanisms for various ventricular morphologies of stress-induced cardiomyopathy. Diagnosing PE especially in a patient with characteristics of acute coronary syndrome such as stressinduced cardiomyopathy can be difficult. It needs to be highlighted that PE should be considered as a potential stressor once the reverse takotsubo syndrome is suspected.

\section{References}

1. Nef HM, Möllmann H, Akashi YJ, Hamm CW. Mechanisms of stress (Takotsubo) cardiomyopathy. Nat Rev Cardio/ 2010;7:187-93.

2. Prasad A, Lerman A, Rihal CS. Apical ballooning syndrome (TakoTsubo or stress cardiomyopathy): a mimic of acute myocardial infarction. Am Heart J 2008;155:408-17.

3. Challa S, Ganji JL, Raizada A, Najib MO, Panse PM, Chaliki HP. Takotsubo cardiomyopathy in a patient with pulmonary embolism. Eur $J$ Echocardiogr 2011;12:E39.

4. Todd $K$, Simpson CS, Redfearn DP, Abdollah H, Baranchuk A. ECG for the diagnosis of pulmonary embolism when conventional imaging cannot be utilized: a case report and review of the literature. Indian Pacing Electrophysiol J 2009;9:268-75.

5. SarinS, Elmi F, Nassef L. Inverted T waves on electrocardiogram: myocardial ischemia versus pulmonary embolism. J Electrocardiol 2005; 38:361-3.

6. Hahn JY, Gwon HC, Park SW, et al. The clinical features of transient left ventricular nonapical ballooning syndrome: comparison with apical ballooning syndrome. Am Heart J 2007;154:1166-73.

7. Prasad A. Apical ballooning syndrome: an important differential diagnosis of acute myocardial infarction. Circulation 2007;115:e56-9.

8. Ramaraj R, Movahed MR. Reverse or inverted takotsubo cardiomyopathy (reverse left ventricular apical ballooning syndrome) presents at a younger age compared with the mid or apical variant and is always associated with triggering stress. Congest Heart Fail 2010;16:284-6. 
9. Smedra-Kaźmirska A, Barzdo M, Kowalski J, Szram S, Berent J. [Takotsubo cardiomyopathy in a man with cerebral haemorrhage.] Anestezjol Intens Ter 2010;42:85-9.

10. Van de Walle SO, Gevaert SA, Gheeraert PJ, De Pauw M, Gillebert TC. Transient stress-induced cardiomyopathy with an "inverted takotsubo" contractile pattern. Mayo Clin Proc 2006;81:1499-502.

11. Patankar GR, Choi JW, Schussler JM. Reverse takotsubo cardiomyopathy: two case reports and review of the literature. J Med Case Rep 2013;7:84.
12. Hurst RT, Askew JW, Reuss CS, et al. Transient midventricular ballooning syndrome: a new variant. J Am CollCardio/ 2006;48:579-83.

13. Ueyama $T$, Kasamatsu $K_{1}$ Hano $T_{1}$ Tsuruo $Y$, Ishikura F. Catecholamines and estrogen are involved in the pathogenesis of emotional stressinduced acute heart attack. Ann N Y Acad Sci 2008;1148:479-85.

14. Park $\mathrm{HE}_{1}$ Kim JH, Yoon YE, et al. A unique case of transient midventricular ballooning: an atypical manifestation of stress-induced cardiomyopathy involving both ventricles. Korean Circ J 2008;38:677-80. 